\title{
Some Unresolved Issues of Measuring the Efficiency of Pollinators: Experimentally Testing and Assessing the Predictive Power of Different Methods
}

\author{
Ram Chander Sihag (D) \\ Laboratory of Animal Behavior and Simulated Ecology, Department of Zoology, CCS Haryana Agricultural University, \\ Hisar 125004, India \\ Correspondence should be addressed to Ram Chander Sihag; sihagrc@rediffmail.com
}

Received 17 June 2018; Revised 30 October 2018; Accepted 27 November 2018; Published 13 December 2018

Academic Editor: Panos V. Petrakis

Copyright (C) 2018 Ram Chander Sihag. This is an open access article distributed under the Creative Commons Attribution License, which permits unrestricted use, distribution, and reproduction in any medium, provided the original work is properly cited.

\begin{abstract}
Knowledge of efficiency of pollinators is valuable in the derivation of (i) the degree of mutualism specialization of a flower visitor in the natural plant communities, (ii) the optimum number of pollinators needed for the maximum pollination in a plant population, and (iii) the pollinator risk assessment in the sustainable agriculture. Earlier researchers used many direct and indirect methods for measuring the pollination efficiency (PE) of flower visitors. However, a great ambiguity exists in the usage of this terminology that necessitated its fresh scrutiny. I tested the available three standard methods afresh to find the efficiency of pollinators. These included comparing the (i) number of pollen grains removed and deposited by the visitors; (ii) seed set resulting from a single and the multiple visits of the visitors; and (iii) "pollen transfer efficiency (PTE)" derived from the foraging behavior and abundances of the visitors. Observations were recorded on the visitors of four plant species in an agroecosystem of Northwest India. These plants represented a wide variety of the floral types across the angiosperms. The first two methods, namely, the "number of pollen grains removed and deposited" and the "seed set resulting from a single and the multiple visits," were appropriate in finding differences between the efficiency ranks of the pollinators of those flowers where the number of deposited pollen grains was less than the number of ovules in the ovary. However, these two methods completely failed in situations where exactly reverse condition of pollen grains and ovules existed. Thus, these two methods of measuring the PE of visitors had limited approach and lacked a universal application over the entire angiosperm taxa. On the other hand, use of "pollen transfer efficiency", derived from the foraging behavior and abundance of the visitors, seemed to have an edge over the other two methods as this was helpful in finding differences between the efficiency ranks of the pollinators of plants in all the three situations tested in this study. However, validation of all the three methods through the plant reproductive potential seemed to be an integral confirmatory step for drawing inferences about the efficiency of pollinators.
\end{abstract}

\section{Introduction}

Pollinator-plant relationship has been the subject of great interest to many pollination biologists. A perfect relationship is witnessed when both components exhibit interdependence (equally benefitted); although the latter may be obligatory (mutualism) or facultative (protocooperation). In the pollinator-plant system, while mutualism is quite rare (e.g., in the fig and fig wasp) [1], there is a very common occurrence of protocooperation. In fact, majority of the plant pollinator relationships fall in the latter category. Here, the plant offers the floral reward to the pollinator and, in return, tries to take the benefit of pollination of its flowers by the pollinator. While the flower visitor successfully harvests the floral reward, the plant reproductive success is not always guaranteed. The real problem arises when the pollinator takes the benefit of floral reward but does not return equal benefit to the plant in terms of its reproductive success. Under such a situation, the major concern of the pollination biologists has been the measurement of degree of interdependence of the two components of this system [2-4]. This degree of interdependence can be measured by a parameter of the pollinator that is popularly known as pollination efficiency (PE). The knowledge of pollination efficiency of flower 
visitors is considered to be valuable in determining the degree of mutualism specialization of the flower visitors to a plant species in the natural communities [5]. Besides this, it helps characterize the most efficient pollinator of a plant species; the derived $\mathrm{PE}$ is an integral part of a method used for determining the optimum number of pollinators needed to maximize pollination in a plant population [6] and is important parameter for the risk assessment in the pollinator conservation and sustainable agriculture [4].

Many indirect and direct methods were earlier used to measure the pollination efficiency of flower visitors. These included examining the full range of floral visitors in a natural community [7-13]; analysis of identity, placement, and quantity of pollen grains on a visitor's body and observation of their foraging behavior [14], examining the number of pollen grains transported $[7,15,16]$, the degree of pollen removal [17], the amount of pollen deposited on the stigma $[12,18]$, or devising index values by supplementing behavioral data with the abundance of flower visitors [19-23]. Some researchers have correlated this with the number of pollinator visits or their visitation rate $[8,9,13,24-31]$, while others have combined the behavioral observations of flower visitors with the pollen loads they deposit on the receptive stigmas $[27,32,33]$. Likewise, some researchers have designated the seed set efficiency as the pollination efficiency $[5,8,34-37]$, while others have correlated seed set with the number of deposited pollen grains $[7,15,27,38,39]$.

Examining the full range of visitors and number of pollen grains removed and deposited will be useful if their relative benefit to the plant is also known. Likewise, the seed set resulting from a single visit [34] or fruit set resulting from the multiple visits [40] of the visitors were considered as suitable methods of measuring the pollination efficiency. However, all the visits of a pollinator to a flower type are not always alike; there are qualitative as well as quantitative temporal variations in these visits [20-23]. Thus, it is not known in how many of the flower types the latter methods hold good. Therefore, each method of measuring the efficiency of pollinators appears to have some limitation. Neeman et al. [4] presented an excellent review on this subject. They too reported the prevailing ambiguity in defining and measuring the efficiency of pollinators. Broadly they identified two methods of measuring the pollination efficiency. First method estimates stigmatic pollen deposition and the underlying pollinator behavioral parameters, while the second method estimates the pollinator's contribution to the plant reproductive success in terms of seed set. They proposed conceptual framework with a modular approach based on pollen deposition, visit frequency, and contribution to seed set relative to the plant's maximum female reproductive potential. Central to these issues, I experimentally tested the latter three methods (pollen deposition, visit frequency, and contribution to seed set) of measuring the pollination efficiency of flower visitors of four plant species, keeping in view the maximum reproductive potential of the female flower as the standard asymptote. This study has been made to resolve the problem of existing ambiguity and to suggest a suitable measure of the pollination efficiency of the flower visitors.

\section{Materials and Methods}

2.1. Floral Situations. There are four floral situations across the angiosperms (the flower-bearing plants) [2]. These are as follows.

(i) Bisexual and Single Flowers. This situation is found in racemes, spikes, spikelets, and cymes of plant families Caesalpinioideae, Cruciferae, Labiatae, Linaceae, Malvaceae, Orchidaceae, Papilionaceae, Pedaliaceae, Rosaceae, Solanaceae, etc. Here the pollination unit is a single flower, i.e., euanthium [1].

(ii) Bisexual and Aggregated Flowers. This situation exists in some inflorescences like corymb, umbel, and capitulum of families Asteraceae, Mimosoideae, Apiaceae, and Vitaceae and the plants like onion (Allium cepa L.). In these cases, the pollination unit is the whole inflorescence, i.e., pseudanthium [1].

(iii) Unisexual and Single Flowers. This situation is found in the inflorescences like racemes and cymes of families Cucurbitaceae and Euphorbiaceae and some members of the Rutaceae, Tiliaceae, etc. Here also, the pollination unit is a single flower, i.e., euanthium [1].

(iv) Unisexual and Aggregated Flowers. This situation prevails in plants of the families like Araceae, Moraceae, Palmaceae, Salicaceae, Typhaceae, etc. The plants are monoecious or dioecious. Here, male and female flowers are either in the same or in different inflorescences; examples of such inflorescences are catkin and hypanthodium of Moraceae. In these cases too, the pollination unit is the whole inflorescence, i.e., pseudanthium [1].

Northwest India lacks undisturbed and large natural ecosystems. The latter have now been converted in to an agroecosystem where large varieties of summer and winter crops are grown. Therefore, I conducted experiments on four cultivated crop plants and their flower visitors at the Research Farms of Haryana Agricultural University, Hisar (India). I selected two crops, namely, alfalfa (Medicago sativa L.) and toria (Brassica campestris L. var. toria) for the first situation, carrot (Daucus carota L. var. sativa) for the second situation, and bath sponge (Luffa cylindrica L.) for the third situation; however, no plant was available for the fourth situation. All the four plants need cross-pollination of their flowers for setting fruits/ seeds [41]. In alfalfa, the ovary of the flower has 12 ovules and tripping of its flowers is a prerequisite for pollination/seed set [42]. Toria is a self-incompatible plant and its flower has 24 ovules [43]. In carrot each flower has 2 ovules; however, a protandrous condition is prevalent in the flowers [44]. In bath sponge, the flowers are unisexual and the female flower has more than 1000 ovules [45]. This information is essential for having knowledge about the maximum reproductive potential of the flower of a plant species.

I tested the following three methods for measuring the pollination efficiency of flower visitors. 
2.2. Number of Pollen Grains Removed and Deposited as a Method of Measuring the Pollination Efficiency. To find out the number of pollen grains removed from the anthers of a flower by the visitors, I used the method of Parker [46, 47]. The foragers of a visiting species were captured randomly from the respective field. Their scopa were clipped and the remaining body of each forager was immersed separately in a $10 \mathrm{ml}$ solution of 60 percent alcohol in a wide glass tube. The contents were shaken well and a volume of $0.25 \mathrm{ml}$ of liquid containing the pollen was flown underneath the cover slip of the hemocytometer. Number of pollen grains present in the five small squares was recorded following procedure explained by Fuentes [48]. The observations were repeated 5 times on one individual and on 10 individuals of a species without replacement of liquid in the tube, thus making 50 observations. In each observation, number of pollen grains present in the solution was determined with the help of the following equation:

$$
\mathrm{N}=\left(\frac{1}{5}\right) \times\left[\frac{\mathrm{n}}{0.0001}\right] \times \mathrm{Vi}
$$

where $\mathrm{N}$ is total number of pollen grains in Vi ml of solution, $\mathrm{n}$ is number of pollen grains in a small square, and Vi is volume of the solution containing total pollen grains at the time of taking ith sample; $i$ takes a value from 1 to $\mathrm{z}$ (in the present case $\mathrm{z}=5$ ).

Likewise, the number of pollen grains deposited on the stigma of the flower by a visitor was calculated using the method of Bertin [10]. The stigmas of flowers of a plant were excised after $24 \mathrm{~h}$ of their pollination and stained with acid fuchsine for half an hour. The pollen grains, stained in magenta color, were counted under $\times 100$ magnification. Ample care was taken in ascertaining the accuracy in counting the pollen grains. The observations in both the cases were repeated five times and on 10 stigmas $(\mathrm{N}=10 \times 5=50)$.

\subsection{Seed/Fruit Set Resulting from a Single and the Multiple} Visit(s) as a Method of Measuring the Pollination Efficiency. Effects of a single visit of the visitors on the seed/fruit set/yield were recorded using method of Spears [34] and effect of multiple visits of the visitors on the seed/fruit set/yield was recorded using method of Donovan and Read [40]. A floral bud due to open next day was marked/tagged in the evening and allowed for the visits of pollinator(s) next morning. Such flowers of each plant species $(\mathrm{N}=40)$ receiving a single and the multiple visit (s) were bagged till fruit set. These marked fruits were harvested on maturity and the number of seeds set in each fruit was manually recorded [49].

\subsection{Pollen Transfer Efficiency as a Method of Measuring the Pollination Efficiency}

2.4.1. Foraging Modes of the Flower Visitors. Effectiveness of the visits of a flower visitor depends on its foraging modes on the flowers of a plant species. On the basis of foraging modes of the flower visitors, I observed three kinds of visits and hence the flower visitors. These are as follows.

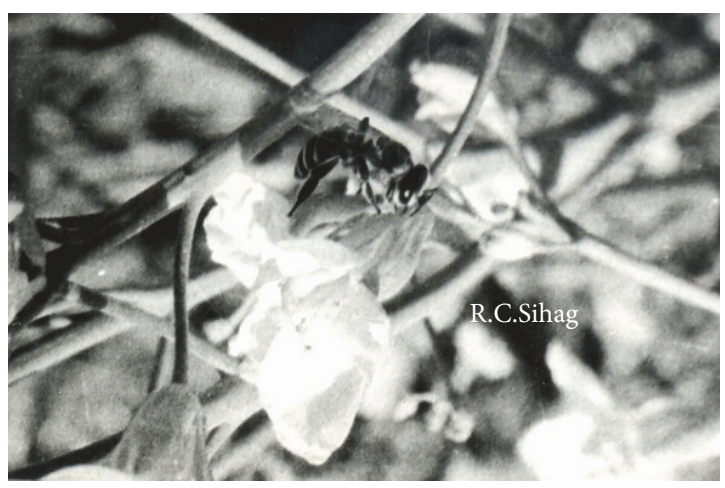

Figure 1: A forager of the dwarf honeybee (Apis florea F.) thieving nectar from the side or base of the flower of cauliflower (Brassica oleracea L. var. botrytis).

(a) Only Nectar Collection (N-Foragers). During this foraging mode, the visitors collected only nectar and that too from the sides or base or from the wide gap between the reproductive column and the corolla of the flower; this is base working $[50,51]$. These foragers were nectar thieves and did not transfer pollen and hence were not the pollinators (Figure 1). These visitors were designated as $\mathrm{N}$-foragers (nectar thieves). Nectar robbers, as defined by Inouye [50] were absent in this study.

(b) Nectar as well as Pollen Collection (NP-Foragers). During this mode, the visitors collected both nectar and pollen in each visit. They did this either from the front of the flower (designated here as top foragers or front foragers or NP1-foragers) (Figure 2) or after collecting pollen from the front/top of the flower they collected nectar from the side of the flower or vice versa (NP2-foragers) (Figure 3). In this case, while foraging from the front of the flower, the forager advertently or inadvertently got dusted with and transferred pollen. The foragers showing this mode always acted as pollinators. These visitors were designated as NP-foragers.

(c) Only Pollen Collection (P-Foragers). In this case, visitors collected pollen only and, while working on a flower/inflorescence, did not attempt to collect nectar (Figure 4). The visitors were front/top foragers. The foragers of a species showing this mode were always pollinators. These visitors were designated as P-foragers; pollen thieves/robbers were, however, absent in this study.

Accordingly, the visitors to the flowers of the plants of this study were designated as pollinators or nonpollinators [51-53]. While working on the flowers of a plant, if a forager worked from the top of the flower, collected pollen in each foraging effort/visit, virtually came in contact with the reproductive organs (anthers and stigma) of the flower, and transferred pollen in its next visit to the succeeding flower, this visitor was designated as a pollinator of the reference plant. However, if the forager of a species worked from the side of the flower to steal only nectar and did not come in contact with the reproductive organs of the flower, this 


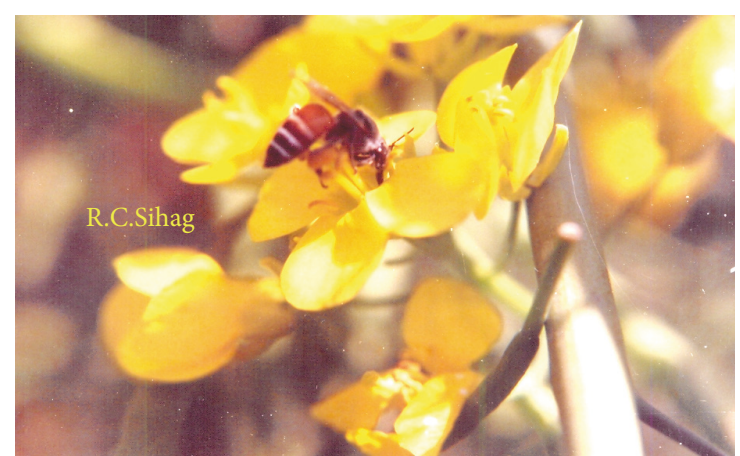

FIGURE 2: A forager of the dwarf honeybee (Apis florea F.) collecting nectar as well as pollen from the top/front of the flower of rape toria (Brassica campestris L. var. toria) (NP1-forager).

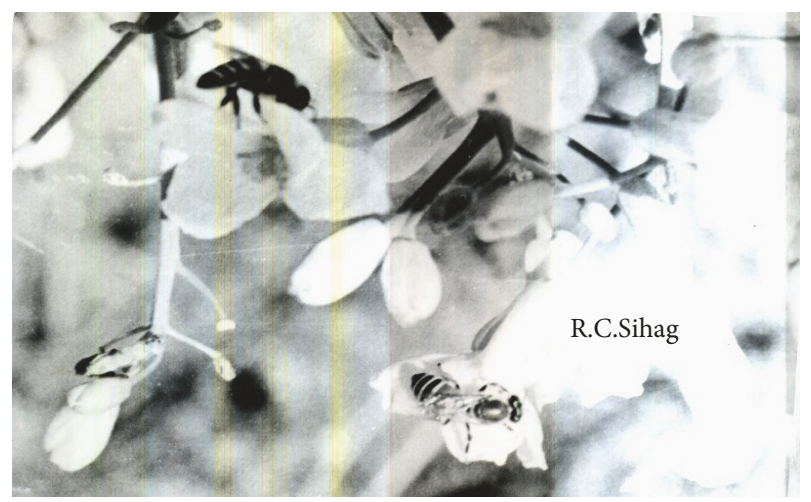

Figure 3: A forager of the dwarf honeybee (Apis florea F.) moving to collect (thieve) nectar from the side of the flower after collecting pollen from the top/front of the flower of rape toria (Brassica campestris L. var. toria) (NP2-forager).

forager was designated as a nonpollinator (nectar thief) of the reference plant.

Thus, all the visits of a pollinator to a flower type were not always alike. A visit that resulted in pollen transfer (e.g., of a $\mathrm{P}$ - or an NP-forager) was termed as 'pollen transferring visit' whereas a visit that did not transfer pollen was termed as a 'nonpollen transferring visit' (e.g., of an $\mathrm{N}$-forager).

2.4.2. Derivation of Pollen Transfer Efficiency. According to Sihag [2], pollen transfer efficiency (PTE) is the result of three parameters of a pollinator species, namely, its (a) foraging mode, (b) foraging rate, and (c) abundance on a plant species. It is an attribute of a species as a whole. Numerically, it is the average number of flowers actually pollinated by a forager per unit time (say per minute). It is different from the 'visitation frequency' or 'foraging rate'; the latter two terms represent the number of flowers visited by a forager per unit time without taking into consideration how many of the visited flowers are pollinated.

If $\mathrm{N}_{\mathrm{i}}$ is the total population of a pollinator on a plant and $\mathrm{N}_{\mathrm{ij}}$ the number of foragers showing jth foraging mode at ith hour of the day (all the three foraging modes are included) so that $\mathrm{P}_{\mathrm{ij}}=\mathrm{N}_{\mathrm{ij}} / \mathrm{N}_{\mathrm{i}}$. Further, if hourly observations are recorded

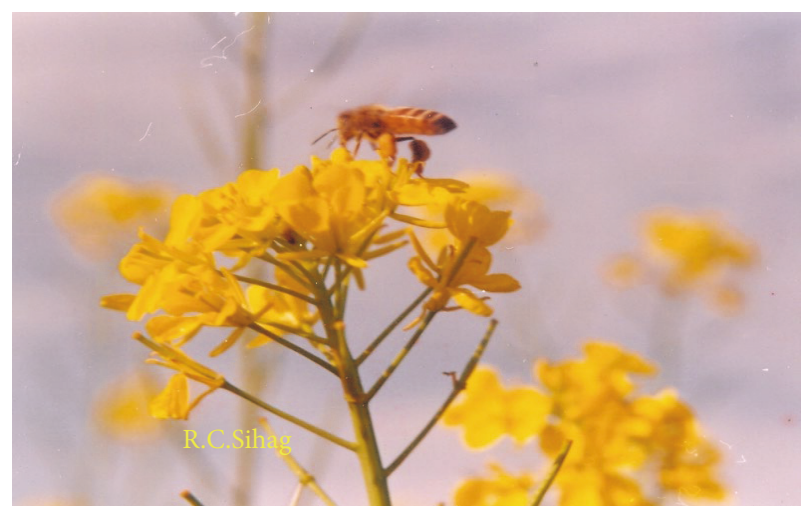

FIGURE 4: A forager of the European honeybee (Apis mellifera F.) collecting only pollen from the top/front of the flower of turnip (Brassica rapa L.) (P-forager).

at $\mathrm{i}$ occasions on a single day and for $\mathrm{m}$ weeks so that $\mathrm{i} \times \mathrm{m}=\mathrm{n}$, then the following model equations will be used for deriving the PTE under the four floral situations:

(i) Pollination of Bisexual and Single Flowers. In this case, only one forager at a time can work on a flower and the visitor of such flowers travels from one flower to the other (Figures $1-4)$.

(a) When All the Visitors of a Species Show Only One (Same) Kind of Foraging Mode. Here all the visitors of a species show similar foraging mode that leads to successful pollination [2], for example, pollen as well as nectar collection from the top of the flower (Figures 2 and 3), or only pollen collection (Figure 4). Then foraging rate of a species will be its pollen transfer efficiency. Here, the model equation will be

$$
\mathbf{P T E}=\mathbf{F} \times \mathbf{R}
$$

where $\mathrm{F}$ is foraging coefficient always taking a value equal to unity under the assumption that all the foraging attempts of a visitor result in successful pollination and $\mathrm{R}$ is foraging rate of a visitor species, as defined earlier.

(b) When Different Visitors of a Species Show Different (More Than One) Kind of Foraging Modes. Here, the foragers of a visitor species show more than one foraging mode simultaneously or at different hours of the day, e.g., only nectar collection (Figure 1), only pollen collection (Figure 4), and nectar as well as pollen collection (Figures 2-3). Then, an empirical model incorporating the temporal variation in visitor's abundance as well as foraging rates will define its pollen transfer efficiency [2]. Here, the model equation will be

$$
\mathbf{P T E}=\frac{1}{\mathrm{n}}\left[\sum_{\mathrm{i}=1}^{\mathrm{n}} \sum_{\mathrm{j}=1}^{3} \mathbf{P}_{\mathrm{ij}} \times \mathbf{F}_{\mathrm{j}} \times \mathbf{R}_{\mathbf{j}}\right]
$$

where $\mathrm{n}$ is number of times in a single day when observations were recorded, $R_{j}$ is foraging rate of the visitors exhibiting $j$ th foraging mode where $\mathrm{j}$ takes a value from 1 to 3 . 


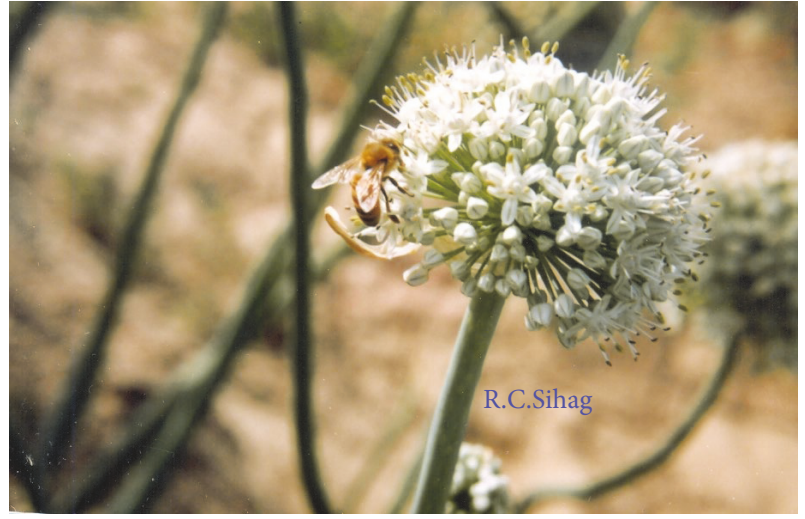

FIgURE 5: A forager of the European honeybee (Apis mellifera L.) collecting nectar as well as pollen from the top/front of the flower of onion (Allium cepa L.).

Then, $R_{1}$ is foraging rate of only pollen collectors, $R_{2}$ is foraging rate of nectar as well as pollen collectors, and $\mathrm{R}_{3}$ is foraging rate of only nectar collectors. Fj is foraging coefficient for the $j$ th foraging mode. $F_{j}$ takes a value 0 or 1 . When coupled with $R_{1}$ and $R_{2}$, its value is equal to one (i.e., $\left.\mathrm{F}_{1}=\mathrm{F}_{2}=1\right)$. Here, a flower visitor always acts as a pollinator. Similarly, when coupled with $R_{3}$, its value is equal to zero. In this case, a flower visitor acts as a nectar thief/robber and plays no role in the process of pollination (i.e., $F_{3}=0$ ).

(ii) Pollination of Bisexual Flowers Which Are Aggregated, with Exposed Reproductive Organs and of the Sizes Smaller Than the Pollinators. The visitors to such flowers show two behavior patterns: (i) nectar as well as pollen collection: they move from one floret to the other (Figure 5); and (ii) only pollen collection: they rush over the floral disc/platform/ball and scatter pollen over several stigmas in each foraging attempt. Here, the model equation will be

$$
\mathbf{P T E}=\frac{1}{\mathrm{n}}\left[\sum_{\mathrm{i}=1}^{\mathrm{n}} \sum_{\mathrm{j}=1}^{2} \mathbf{P}_{\mathrm{ij}} \times \mathbf{F}_{\mathrm{j}} \times \mathbf{R}_{\mathbf{j}}\right]
$$

where $\mathrm{n}$ is number of times in a single day when observations were recorded and $\mathrm{R}_{\mathrm{i}}$ is foraging rate of the visitors exhibiting $j$ th foraging mode where $j$ takes a value from 1 to 2 .

Then, $R_{1}$ is foraging rate of only pollen collectors, $R_{2}$ is foraging rate of nectar as well as pollen collectors, and $\mathrm{Fj}$ is foraging coefficient for the $\mathrm{jth}$ foraging mode. When coupled with $R_{1}$ and $R_{2}, F_{j}$ always takes a value equal to 1 (i.e., $F_{1}=F_{2}$ $=1$ ). Here flower visitors always act as pollinators.

However, if the plant reproductive organs are concealed or the size of the pollinator is equal to or smaller than the size of the flower, despite the inflorescence representing a single floral unit, each flower requires independent visits to be pollinated very much like a bisexual and single flower [2].

(iii) Pollination of Unisexual and Single Flowers. In the unisexual flowers (Figure 6), a female flower will be pollinated only if a forager has already visited a male flower [2]. Here, a component of conditional probability has entered into the

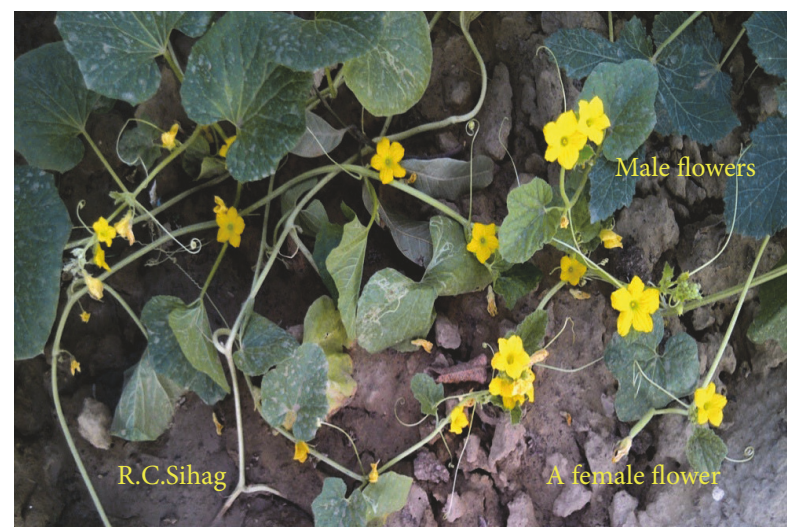

FIGURE 6: Male biased sex ratio in the flowers of a cucurbit plant; the probability of visit of a pollinator to the female flower will depend upon this ratio.

process for the successful pollination of a female flower. The value of probability depends upon the female to male sex ratio in the floral population (Figure 6). There can be two situations.

(a) When All the Foragers of a Species Show Only One (Same) Kind of Foraging Mode. Here other conditions are the same for (2a); the only difference is the presence of a probability component. Therefore, the model equation will be

$$
\mathbf{P T E}=\mathbf{F} \times \mathbf{R} \times \mathbf{P}_{\mathrm{c}}
$$

where $\mathrm{P}_{c}$ is conditional probability. This is the probability of a forager visiting a female flower subject to the condition that it has already visited a male flower. $\mathrm{P}_{\mathrm{c}}$ will depend on the ratio of male: female flowers and can be derived using the following relationship:

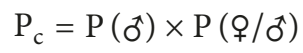

where $\mathrm{P}\left(\mathrm{o}^{\star}\right)$ is probability of a forager visiting a male flower and $\mathrm{P}\left(\mathrm{Q} / ठ^{\star}\right)$ is probability of a forager visiting a female flower given that the visitor has already visited a male flower.

(b) When Different Visitors of a Species Show Different (More Than One) Kinds of Foraging Modes. Here the model equation will be

$$
\mathbf{P T E}=\frac{1}{\mathrm{n}}\left[\sum_{\mathrm{i}=1}^{\mathrm{n}} \sum_{\mathrm{j}=1}^{3} \mathbf{P}_{\mathrm{ij}} \times \mathbf{F}_{\mathrm{j}} \times \mathbf{R}_{\mathrm{j}}\right] \times \mathbf{P}_{\mathrm{c}}
$$

The abbreviations are the same as described earlier.

(iv) Pollination of Unisexual and Aggregated Flowers. In this case, the model equation will be

$$
\mathbf{P T E}=\frac{1}{\mathrm{n}}\left[\sum_{\mathrm{i}=1}^{\mathrm{n}} \sum_{\mathrm{j}=1}^{2} \mathbf{P}_{\mathrm{ij}} \times \mathbf{F}_{\mathrm{j}} \times \mathbf{R}_{\mathrm{j}}\right] \times \mathbf{P c}
$$

The abbreviations are the same as described earlier. 
TABLE 1: Number of pollen grains carried by different visitor species foraging on four plants.

\begin{tabular}{|c|c|c|c|c|}
\hline \multirow[t]{2}{*}{ Visitor species } & \multicolumn{4}{|c|}{$\begin{array}{l}\text { Number of pollen grains carried by different visitor } \\
\text { species foraging on four plants }\end{array}$} \\
\hline & Alfalfa & Toria & Carrot & Bath sponge \\
\hline Andrena ilerda & - & $1425 \pm 10.1$ & - & - \\
\hline Andrena leaena & - & - & $1240 \pm 9.3$ & - \\
\hline Apis dorsata & $1475 \pm 9.3$ & $1525 \pm 11.9$ & - & - \\
\hline Apis florea & $\mathrm{nt}$ & $1335 \pm 10.3$ & $1205 \pm 8.6$ & $1269 \pm 5.8$ \\
\hline Apis mellifera & $1350 \pm 11.9$ & $1475 \pm 13.6$ & - & - \\
\hline $\begin{array}{l}\text { Chalicodoma } \\
\text { cephalotes }\end{array}$ & $1235 \pm 8.5$ & - & - & - \\
\hline $\begin{array}{l}\text { Chalicodoma } \\
\text { rubripes }\end{array}$ & $1310 \pm 7.9$ & - & - & - \\
\hline Megachile nana & $1285 \pm 10.3$ & - & - & - \\
\hline Halictus sp. & - & - & - & $1406 \pm 8.7$ \\
\hline Melissodes sp. & - & - & - & $1835 \pm 12.6$ \\
\hline Syrphid flies & - & $1210 \pm 7.6$ & $183 \pm 3.4$ & - \\
\hline Xylocopa fenestrata & - & - & - & $2850 \pm 21.1$ \\
\hline $\operatorname{LSD}(p<0.05)$ & 21.78 & 20.6 & 13.8 & 77.3 \\
\hline
\end{tabular}

2.4.3. Recording of Empirical Data. To record the numbers of flower visitors, five plots of $1 \times 1 \mathrm{~m}^{2}$ were randomly selected in the plant area and the number of visitors and their foraging modes (method of working on a flower) and rates (number of flowers visited per minute) were recorded for 5 minutes. Daily observations were recorded from $0900 \mathrm{~h}$ to $1700 \mathrm{~h}$ at two-hour interval (5 daily observations) $[20,48]$ and repeated at weekly intervals during the peak flowering period of the plant for 5 weeks (for each species $n=5 \times 5 \times 5=125$ observations). Respective pollen transfer efficiency (PTE) of the pollinators was calculated from the data on their foraging modes, the foraging rates, and the abundances using (2a), (2b), (3), (4a), and (4b).

2.4.4. Statistical Analysis. All the experiments were laid down in Completely Randomized Design [54] and the recorded data were statistically analyzed using one- or two-way Analysis of Variance (as the need was). This was followed by a derivation of 'least significance difference' (LSD) to compare the treatment means at 5 per cent level of significance.

\section{Results}

3.1. Number of Pollen Grains Removed and Deposited as a Method of Measuring the Pollination Efficiency. On the basis of number of pollen grains removed by the flower visitors and deposited on the stigmas of four plants of this study, the pollinators could be clearly ranked for their efficiency (Tables 1 and 2), as the differences among the pollinators for these two parameters were significant (ANOVA followed by LSD; $\mathrm{p}<0.05$, Tables 1 and 2). For example, the efficiency ranks of pollinators of alfalfa were A. dorsata $>$ A. mellifera $>$ C. rubripes $>M$. nana $>C$. cephalotes; of toria were A. dorsata $>$ A. mellifera $>$ Andrena ilerda $>$ A. florea $>$ syrphid flies; and of carrot were Andrena leaena $>$ A. florea $>$ syrphid flies, respectively. However, if examined in the light of female reproductive asymptote of flowers of these plants, this measure of PE seemed to be illogical. This is because, all the pollinators of alfalfa, toria, and carrot removed and deposited much larger numbers of pollen grains than required by the flower of the respective plant, as is evident from the number of ovules present in the respective ovary. Here, every visitor is capable of transferring the required number of pollen grains to set (maximum) seeds in the visited flower. Hence, on the basis of this method of measuring the PE of flower visitors, the difference in the relative contributions of visitors towards the reproductive success of the plant is difficult to be established. Bath sponge, however, presented an entirely different picture. On the basis of the above two parameters and the number of ovules in the ovary, the pollinators of bath sponge could be ranked more precisely and logically (Tables 1 and 2). The pollinators of bath sponge deposited much lower number of pollen grains than required by the flower as is indicated by the number of ovules in the flower of this plant; X. fenestrata had a clear edge over Melissodes sp., Halictus sp., and A. florea, and their efficiency ranks too were in this descending order.

These two submethods of measuring the PE (i.e., pollen removed and deposited) of flower visitors, though successfully differentiated the pollinators of one plant (bath sponge) for their efficiency, yet failed to do so in case of pollinators of other three plants (alfalfa, toria, and carrot) of this study; these methods have limited scope and certainly lack universal application in determining the efficiency of pollinators.

\subsection{Seed/Fruit Set Resulting from a Single and the Multiple} Visit(s) as a Method of Measuring the Pollination Efficiency. Results in Table 3 present the number of fruit/seed set due to a single visit of each foraging mode of the pollinators of 
TABLE 2: Number of pollen grains deposited by the visitors on the stigmas of different plant species.

\begin{tabular}{|c|c|c|c|c|}
\hline \multirow{2}{*}{ Visitor species } & \multicolumn{4}{|c|}{ Number of pollen grains deposited on the stigma } \\
\hline & Alfalfa & Toria & Carrot & Bath sponge \\
\hline A. ilerda & - & $56 \pm 11.7$ & - & - \\
\hline A. leaena & - & - & $19 \pm 6.8$ & - \\
\hline A. dorsata & $49 \pm 2.8$ & $73 \pm 11.5$ & - & - \\
\hline A. florea & nt & $48 \pm 10.2$ & $16 \pm 5.2$ & $235 \pm 23.2$ \\
\hline A. mellifera & $44 \pm 3.3$ & $63 \pm 9.8$ & - & - \\
\hline C. cephalotes & $29 \pm 3.5$ & - & - & - \\
\hline C. rubripes & $40 \pm 3.1$ & - & - & - \\
\hline M. nana & $34 \pm 4.7$ & - & - & - \\
\hline Halictus sp. & - & - & - & $292 \pm 28.9$ \\
\hline Melissodes sp. & - & - & - & $454 \pm 32.4$ \\
\hline Syrphid flies & - & $33 \pm 7.3$ & $11 \pm 3.5$ & - \\
\hline$X$. fenestrata & - & - & - & $1109 \pm 71.3$ \\
\hline L.S.D. $(p<0.05)$ & 3.4 & 6.3 & 1.8 & 23.6 \\
\hline
\end{tabular}

* Mean \pm SD of 50 observations; values have been rounded off to the nearest whole number; $\mathrm{nt}=$ species acted as a nectar thief; -: pollinator species was not present.

TABLE 3: Fruit/seed set in flowers of four plant species resulting from a single visit of three foraging modes of different visitors.

Visitor species

Only nectar foraging

$(\mathrm{N})$

\section{Alfalfa}

A. dorsata

0

A. florea

C. cephalotes

C. rubripes

M. nana

Toria
A. ilerda
A. dorsata
A. florea
A. mellifera

Carrot

A. leaena
A. florea
Syrphid sp.
Bath sponge

A. florea

Halictus sp.

0

Melissodes sp.

$X$. fenestrata

0

$-$

$-$
Per cent fruit/ seed set in flowers of four

plants due to a single visit of three foraging modes of different visitors *

Only pollen foraging (P)

$100(12.0 \pm 0.0)$

$\begin{array}{ll}- & 100(24.0 \pm 0.0) \\ - & 100(24.0 \pm 0.0) \\ 0 & 100(24.0 \pm 0.0) \\ 0 & 100(24.0 \pm 0.0)\end{array}$

$100(2.0 \pm 0.0)$

$100(2.0 \pm 0.0)$

$100(2.0 \pm 0.0)$

$100(147.0 \pm 28.3)$

$100(205.0 \pm 43.6)$

$100(263.0 \pm 58.5)$

$100(703.0 \pm 146.2)$
Nectar as well as pollen foraging (NP)

$$
\begin{gathered}
100(12.0 \pm 0.0) \\
0 \\
100(12.0 \pm 0.0) \\
100(12.0 \pm 0.0) \\
100(12.0 \pm 0.0)
\end{gathered}
$$

$100(24.0 \pm 0.0)$

$100(24.0 \pm 0.0)$

$100(24.0 \pm 0.0)$

$100(24.0 \pm 0.0)$

$100(2.0 \pm 0.0)$

$100(2.0 \pm 0.0)$

$100(2.0 \pm 0.0)$

$100(155.0 \pm 39.8)$

$100(198.0 \pm 48.3)$

$100(272.0 \pm 69.4)$

$100(693.0 \pm 132.8)$

Based on 40 observations, figures in the parentheses represent number of seeds set per flower; $\mathrm{t}\left(\mathrm{p}>0.05 ; \mathrm{df}_{38}\right)$ between $\mathrm{P}$ and $\mathrm{NP}=$ nonsignificant for all the plants; $\mathrm{F}(\mathrm{p}>0.05)$ between pollinators = nonsignificant for alfalfa $\left(d f_{4,194}\right)$, toria $\left(d f_{3,155}\right)$, and carrot $\left(d f_{3,155}\right) ; \mathrm{F}\left(\mathrm{p}<0.05, d f_{3,155}\right)$ between pollinators $=$ significant for bath sponge; -: pollinator behavior was absent. 
TABLE 4: Fruit/seed set resulting from multiple visits of different flower visitors of four plant species.

Visitor species

Number of seed set resulting from multiple visits of pollinators of four plants ( figures in the parentheses are means of numbers of seed set per flower)*

1

2

3

4

\begin{tabular}{|c|c|c|c|c|}
\hline \multicolumn{5}{|l|}{ Alfalfa (a)* } \\
\hline A. dorsata & $100(12.0 \pm 0.0)$ & $100(12.0 \pm 0.0)$ & $100(12.0 \pm 0.0)$ & $100(12.0 \pm 0.0)$ \\
\hline A. florea & 0 & 0 & 0 & 0 \\
\hline C. cephalotes & $100(12.0 \pm 0.0)$ & $100(12.0 \pm 0.0)$ & $100(12.0 \pm 0.0)$ & $100(12.0 \pm 0.0)$ \\
\hline C. rubripes & $100(12.0 \pm 0.0)$ & $100(12.0 \pm 0.0)$ & $100(12.0 \pm 0.0)$ & $100(12.0 \pm 0.0)$ \\
\hline M. nana & $100(12.0 \pm 0.0)$ & $100(12.0 \pm 0.0)$ & $100(12.0 \pm 0.0)$ & $100(12.0 \pm 0.0)$ \\
\hline \multicolumn{5}{|l|}{ Toria $(a) *$} \\
\hline A. ilerda & $100(24.0 \pm 0.0)$ & $100(24.0 \pm 0.0)$ & $100(24.0 \pm 0.0)$ & $100(24.0 \pm 0.0)$ \\
\hline A. dorsata & $100(24.0 \pm 0.0)$ & $100(24.0 \pm 0.0)$ & $100(24.0 \pm 0.0)$ & $100(24.0 \pm 0.0)$ \\
\hline A. florea & $100(24.0 \pm 0.0)$ & $100(24.0 \pm 0.0)$ & $100(24.0 \pm 0.0)$ & $100(24.0 \pm 0.0)$ \\
\hline A. mellifera & $100(24.0 \pm 0.0)$ & $100(24.0 \pm 0.0)$ & $100(24.0 \pm 0.0)$ & $100(24.0 \pm 0.0)$ \\
\hline \multicolumn{5}{|l|}{ Carrot (b)* } \\
\hline A. leaena & $100(2.0 \pm 0.0)$ & $100(2.0 \pm 0.0)$ & $100(2.0 \pm 0.0)$ & $100(2.0 \pm 0.0)$ \\
\hline A. florea & $100(2.0 \pm 0.0)$ & $100(2.0 \pm 0.0)$ & $100(2.0 \pm 0.0)$ & $100(2.0 \pm 0.0)$ \\
\hline Syrphid sp. & $100(2.0 \pm 0.0)$ & $100(2.0 \pm 0.0)$ & $100(2.0 \pm 0.0)$ & $100(2.0 \pm 0.0)$ \\
\hline \multicolumn{5}{|l|}{$\begin{array}{l}\text { Bath sponge } \\
\text { (a) } * *\end{array}$} \\
\hline A. florea & $100(150.0 \pm 31.2)$ & $100(260.0 \pm 56.2)$ & $100(440.0 \pm 88.8)$ & $100(590 . .0 \pm 124.3)$ \\
\hline Halictus sp. & $100(200.0 \pm 45.7)$ & $100(365.0 \pm 88.0)$ & $100(580.0 \pm 126.4)$ & $100(794.0 \pm 188 . .0)$ \\
\hline Melissodes sp. & $100(275.0 \pm 62.6)$ & $100(490.0 \pm 114.8)$ & $100(770.0 \pm 167.0)$ & $100(1179.4 \pm 235.6)$ \\
\hline$X$. fenestrata & $100(700.0 \pm 157.6)$ & $100(1340.0 \pm 288.6)$ & $100(1324.0 \pm 274.8)$ & $100(1344.0 \pm 277.0)$ \\
\hline
\end{tabular}

(a) Based on visits to 40 flowers and (b) based on visits to 5 inflorescences (the number of flowers was variable); $* \mathrm{~F}(\mathrm{P}>0.05)$ visits $=$ nonsignificant; $* \mathrm{~F}(\mathrm{P}$ $>0.05)$ visitors $=$ nonsignificant; $* * \mathrm{~F}(\mathrm{P}<0.05)$ visits $=$ significant; $* * \mathrm{~F}(\mathrm{P}<0.05)$ visitors $=$ significant

four plants. In alfalfa, toria, and carrot, pollen transferring (an NP or a P) single visit of each pollinator was enough in achieving the maximum seed set in the visited flowers. But, none of the nonpollen transferring (an N) visit could do so, as the seed set due to the latter visitors was zero (Table 3). The differences between the two foraging modes (an NP and a $\mathrm{P}$ ) were nonsignificant and also between the pollinator species of these plants (ANOVA followed by LSD; $p>0.05$, Table 3). Differences between these two foraging modes were nonsignificant on bath sponge too (ANOVA followed by LSD; $p>0.05$, Table 3). However, differences among the pollinator species of the latter plant were significant (ANOVA followed by LSD; $p<0.05$, Table 3 ). This indicated that the effects of visits of NP- and P-foragers of the pollinators of four plant species in fruit and seed set were similar. Therefore, it becomes amply clear that all the pollinators of alfalfa, toria, and carrot contributed equally in their pollen transferring single visits towards the respective reproductive success of these three plants. But the pollinators of bath sponge contributed differentially towards the reproductive success of the latter plant (Table 3 ).

The results on the effect of pollen transferring multiple visits of the pollinators of four plants are presented in Table 4. In alfalfa, toria, and carrot; a single (pollen transferring) visit of each pollinator was enough to fully realize the reproductive potential of a flower; the multiple visits were of no added advantage to these three plants. Therefore, on the basis of multiple visits, the rankings of pollinators of alfalfa, toria, and carrot are not of added use. However, in bath sponge, there was an incremental effect of multiple visits of pollinators on its fruit and seed set. The maximum reproductive potential of a female flower of the latter plant seemed to be about 1350 seeds. Apis florea, Halictus sp., and Melissodes sp. could set fruit in this plant in the respective single visit, but these pollinators could not realize the maximum reproductive potential of the female flower of this plant even in their respective four consecutive pollen transferring visits (Table 4). On the other hand, Xylocopa fenestrata could do so in just its two consecutive visits, thus having an edge over the other three pollinators of the bath sponge.

Therefore, on the basis of multiple visits, the ranking of pollinators of only one of the four plants of this study was possible. On the broader angiosperm plate form, this method of measuring the PE too seems to have restricted application.

3.3. Pollen Transfer Efficiency as a Method of Measuring the Pollination Efficiency. The visitors of a plant species showed different foraging modes. On alfalfa (Medicago sativa), Apis florea invariably showed only one kind of foraging mode; foragers of this honeybee were base workers ( $\mathrm{N}$-foragers). 
TABLE 5: Foraging modes, number of foragers, foraging rates, and pollen transfer efficiency of different flower visitors of alfalfa (Medicago sativa).

\begin{tabular}{|c|c|c|c|c|c|c|}
\hline \multirow{2}{*}{ Parameter } & \multirow{2}{*}{ Foraging mode } & \multicolumn{5}{|c|}{ Visitor species } \\
\hline & & Apis dorsata & Apis florea & Chalicodoma cephalotes & Chalicodoma rubripes & Megachile nana \\
\hline \multirow{4}{*}{$\begin{array}{l}\text { No. of foragers } \\
/ \mathbf{m}^{2} \\
\text { (a) }\end{array}$} & $\mathbf{N}$ & $1.87 \pm 0.09$ & $5.81 \pm 0.8$ & 0 & 0 & $0 *(\mathrm{~b})$ \\
\hline & $\mathbf{P}$ & $0.50 \pm 0.001$ & 0 & 0 & 0 & 0 \\
\hline & NP & $0.25 \pm 0.01$ & 0 & $0.23 \pm 0.04$ & $3.6 \pm 0.4$ & $2.70 \pm 0.2 *(\mathrm{c})$ \\
\hline & $\mathbf{N}+\mathbf{P}+\mathbf{N P}$ & $1.89 \pm 0.09$ & $5.81 \pm 0.8$ & $0.23 \pm 0.04$ & $3.6 \pm 0.4$ & $2.70 \pm 0.2 *(\mathrm{c})$ \\
\hline \multirow{3}{*}{$\begin{array}{l}\text { Foraging rate } \\
\text { (per minute) } \\
\text { (a) }\end{array}$} & $\mathrm{N}$ & $7.6 \pm 0.42$ & $4.9 \pm 0.31$ & 0 & 0 & 0 \\
\hline & $\mathbf{P}$ & $7.2 \pm 0.47$ & 0 & 0 & 0 & 0 \\
\hline & NP & $5.8 \pm 0.34$ & 0 & $11.5 \pm 0.52$ & $15.3 \pm 0.43$ & $18.4 \pm 0.3 *(\mathrm{c})$ \\
\hline \multicolumn{2}{|c|}{ PTE (per minute) } & 0.65 & 0.0 & 11.5 & 15.3 & 18.4 \\
\hline
\end{tabular}

a: mean \pm SD of 125 observations; $\mathrm{N}$ : only nectar gathering; P: only pollen gathering; NP: nectar as well as pollen gathering; PTE: Pollen transfer efficiency; * $\mathrm{b}: \mathrm{t}(\mathrm{p}<0.05)=$ significant (values tested on the basis of paired t-test); $* \mathrm{c}$ : F $(\mathrm{P}<0.05)=$ significant (values tested for the visitors of a row); zero values indicate that pollinator behavior was absent.

TABLE 6: Foraging modes, number of foragers, foraging rates, and pollen transfer efficiency of different flower visitors of toria (Brassica campestris).

\begin{tabular}{|c|c|c|c|c|c|}
\hline \multirow{2}{*}{ Parameter } & \multirow{2}{*}{ Foraging mode } & \multicolumn{4}{|c|}{ Visitor species } \\
\hline & & Andrena ilerda & Apis dorsata & Apis florea & Apis mellifera \\
\hline \multirow{4}{*}{$\begin{array}{l}\text { No. of foragers } \\
/ \mathbf{m}^{2}(\mathbf{a})\end{array}$} & $\mathbf{N}$ & 0 & 0 & $3.94 \pm 0.49$ & $0.97 \pm 0.08 *(b)$ \\
\hline & $\mathbf{P}$ & 0 & $0.19 \pm 0.02$ & $1.07 \pm 0.09$ & $0.67 \pm 0.05 *(c)$ \\
\hline & NP & $0.73 \pm 0.05$ & $1.91 \pm 0.18$ & $4.14 \pm 0.52$ & $2.11 \pm 0.21 *(\mathrm{c})$ \\
\hline & $\mathrm{N}+\mathrm{P}+\mathrm{NP}$ & $0.73 \pm 0.05$ & $2.10 \pm 0.20$ & $9.15 \pm 0.10$ & $3.75 \pm 0.50 *(\mathrm{c})$ \\
\hline \multirow{3}{*}{$\begin{array}{l}\text { Foraging rate } \\
\text { (per minute)(a) }\end{array}$} & $\mathbf{N}$ & 0 & 0 & $\mathrm{nt}$ & $\mathrm{nt}$ \\
\hline & $\mathbf{P}$ & 0 & $9.33 \pm 1.4$ & $6.3 \pm 0.72$ & $11.46 \pm 1.35 *(\mathrm{c})$ \\
\hline & NP & $9.39 \pm 1.6$ & $5.5 \pm 0.7$ & $2.50 \pm 0.39$ & $8.45 \pm 0.69 *(\mathrm{c})$ \\
\hline \multicolumn{2}{|c|}{ PTE (per minute) } & 9.39 & 5.85 & 1.87 & 6.80 \\
\hline
\end{tabular}

Abbreviations are as in Table 5 .

Here, this honeybee always acted as a nectar thief (Table 5). Likewise, on this plant, three megachilid species too showed only one kind of foraging mode; i.e., these invariably acted as NP1-foragers (pollinators). However, Apis dorsata exhibited all the three kinds of foraging modes (Table 5); in its NPforaging mode; NP1 was present but NP2 was absent. On toria (Brassica campestris), Apis florea and Apis mellifera showed all the three kinds of foraging modes; nectar thieving was quite common (Table 6). On the other hand, nectar thieving was absent in Apis dorsata ( $\mathrm{N}$-foragers were absent) whereas Andrena ilerda invariably showed P-foraging mode on this plant (Table 6). On carrot (Daucus carota), due to the very small size of the floret and exposed nectary, nectar thieving was not possible; hence $\mathrm{N}$-foragers were absent (Table 7). Andrena leaena and syrphid flies invariably showed only one kind of foraging mode (i.e., NP-foraging). However, Apis florea showed P- as well as NP-foraging modes (Table 7). On bath sponge (Luffa cylindrica), Apis florea, and Halictus species had nectar thieves in their foragers; Melissodes species exhibited two kinds of foraging modes (i.e., P- and NPforaging) whereas Xylocopa fenestrata invariably exhibited only one kind of foraging mode (i.e., NP-foraging, Table 8). Therefore, mere observations on the foraging modes of the pollinators cannot differentiate them for their efficiency.
There were significant differences between the abundances of the pollinators of a plant (ANOVA, $p<0.05$, Tables $5-8$ ) and so also in their foraging rates (ANOVA, $\mathrm{p}<0.05$, Tables 5-8). Apis florea was the most abundant on alfalfa, toria, and carrot. However, its foraging mode disqualified it as a pollinator of alfalfa, and foraging rate was lower than other pollinators on toria and carrot. Therefore, data on the abundance and foraging rate presented a very complex situation. On the basis of these data, it was difficult to draw any conclusion about the ranking of the pollinators for their efficiency. The foraging modes, foraging rates, and visitors' abundances alone were not the suitable measures to describe the pollination efficiency of a visitor species. Therefore, a single resultant value needed to be derived from these parameters to represent the efficiency of the pollinators; hence PTE equations (2a), (2b), (3), (4a), and (4b) presented above were used.

By applying data in these model equations, a single value of PTE for each species could be calculated, and the efficiency of the pollinator of a plant species could be determined (Tables 5-8). In this way, on alfalfa, the order of PTE was $M$. nana $>$ C. rubripes $>C$. cephalotes $>A$. dorsata $>A$. florea; on toria it was: A. ilerda $>A$. mellifera $>A$. dorsata $>$ A. florea; on carrot it was A. leaena $>A$. florea $>$ syrphid flies; and on 
TABLE 7: Foraging modes, number of foragers, foraging rates, and pollen transfer efficiency of different flower visitors of carrot (Daucus carota).

\begin{tabular}{lcccc}
\hline Parameter & Foraging mode & \multicolumn{2}{c}{ Visitor species } \\
& & Andrena leaena & Apis florea & Syrphid flies \\
\hline No. of foragers & $\mathbf{N}$ & 0 & 0 & 0 \\
$/ \mathbf{m}^{2}$ & $\mathbf{P}$ & 0 & $8.45 \pm 0.02$ & 0 \\
$(\mathbf{a})$ & $\mathbf{N P}$ & $1.11 \pm 0.14$ & $6.72 \pm 0.39$ & $7.86 \pm 0.74 *(\mathrm{c})$ \\
& $\mathbf{N}+\mathbf{P}+\mathbf{N P}$ & $1.11 \pm 0.14$ & $15.17 \pm 0.41$ & $7.86 \pm 0.74 *(\mathrm{c})$ \\
\hline Foraging rate & $\mathbf{N}$ & 0 & 0 & 0 \\
(per minute) & $\mathbf{P}$ & 0 & $12.71 \pm 1.41$ & 0 \\
(a) & $\mathbf{N P}$ & $12.1 \pm 2.65$ & $10.1 \pm 1.25$ & $3.05 \pm 0.29 *(\mathrm{c})$ \\
\hline \multicolumn{2}{r}{} & $\mathbf{1 2 . 0 9}$ & $\mathbf{1 1 . 1 7}$ & $\mathbf{3 . 0 5}$ \\
\hline
\end{tabular}

Abbreviations are as in Table 5.

TABLE 8: Foraging modes, number of foragers, foraging rates, and pollen transfer efficiency of different flower visitors of bath sponge $(L u f f a$ cylindrica).

\begin{tabular}{|c|c|c|c|c|c|}
\hline \multirow{2}{*}{ Parameter } & \multirow{2}{*}{ Foraging mode } & \multicolumn{4}{|c|}{ Visitor species } \\
\hline & & Apis florea & Halictus species & Melissodes species & Xylocopa fenestrata \\
\hline \multirow{4}{*}{ No. of foragers $/ \mathrm{m}^{2}(a)$} & $\mathbf{N}$ & $1.84 \pm 0.35$ & $0.25 \pm 0.02$ & - & $-*(\mathrm{~b})$ \\
\hline & $\mathbf{P}$ & $0.38 \pm 0.15$ & $0.15 \pm 0.01$ & $0.13 \pm 0.01$ & $-*(\mathrm{c})$ \\
\hline & NP & $0.46 \pm 0.14$ & $0.28 \pm 0.02$ & $0.28 \pm 0.03$ & $0.73 \pm 0.05 *(\mathrm{c})$ \\
\hline & $\mathrm{N}+\mathrm{P}+\mathrm{NP}$ & $2.68 \pm 0.65$ & $0.48 \pm 0.05$ & $0.41 \pm 0.04$ & $0.73 \pm 0.05 *(\mathrm{c})$ \\
\hline \multirow{3}{*}{ Foraging rate (per minute)(a) } & $\mathbf{N}$ & $\mathrm{nr}$ & $\mathrm{nr}$ & - & - \\
\hline & $\mathbf{P}$ & $3.6 \pm 0.39$ & $3.2 \pm 0.37$ & $3.2 \pm 0.37$ & $-*(\mathrm{c})$ \\
\hline & NP & $2.4 \pm 0.19$ & $1.6 \pm 0.28$ & $2.2 \pm 0.24$ & $6.5 \pm 0.54 *(\mathrm{c})$ \\
\hline \multicolumn{2}{|c|}{$\mathbf{P}_{\mathrm{c}}$ (conditional probability) } & 0.054 & 0.054 & 0.054 & 0.054 \\
\hline \multicolumn{2}{|c|}{ PTE (per minute) } & 0.05 & 0.09 & 0.14 & 0.35 \\
\hline
\end{tabular}

$\mathrm{P}_{\mathrm{c}}$ : derived from ${ }^{\star}: \uparrow$ ratio $=4138: 253$. Other abbreviations are as in Table 5.

bath sponge it was $X$. fenestrata $>$ Melissodes sp. $>$ Halictus sp. $>$ A. florea. Thus, on the basis of the above model equations, PTE of the pollinators could be derived and pollinators of a plant species could be ranked.

Again, how much authentic the latter ranking is in terms of contribution of the pollinators towards the reproductive success of a plant needs confirmation. The validation of these is possible if the maximum reproductive potential (number of ovules in the ovary) of a flower of a plant species and the effect of a single and the multiple visit(s) of the pollinators on the seed set of visited flower are known. For example, alfalfa flower has 12 ovules, its five of the six visitors (namely, Apis dorsata, Apis mellifera, Chalicodoma cephalotes, Chalicodoma rubripes, and Megachile nana) transfer $>29$ number of pollen grains in a single visit (Table 2). Therefore, these five visitors of alfalfa can fully pollinate the visited flower in a single visit and they are contributing equally towards the reproductive success of the plant. However, in practice, it is not so. Megachile nana, Chalicodoma rubripes, Chalicodoma cephalotes, Apis dorsata, and Apis florea pollinated 18.4, 15.3, $11.4,0.65$, and zero (0) flowers per minute (PTE), respectively (Table 5). Therefore, their pollination efficiency is different and is in an order: Megachile nana $>$ Chalicodoma rubripes $>$ Chalicodoma cephalotes $>$ Apis dorsata $>$ Apis florea. Likewise, the order of efficiency on toria is Andrena ilerda $>$ Apis mellifera $>$ Apis dorsata $>$ Apis florea (Table 6), on carrot it is Andrena leaena $>$ Apis florea $>$ syrphid flies (Table 7), and on bath sponge it is X. fenestrata > Melissodes sp. > Halictus sp. $>$ A. florea (Table 8).

Therefore, PTE method of measuring the PE of the flower visitors has certainly a broader and more authentic application than the other two methods. This is because the results on the PTE are more logical than the results on the other two methods of measuring the PE of flower visitors. However, the validation of PTE method too will need the help of knowledge on the reproductive potential of the plant species.

\section{Discussion}

Pollination involves two components, the flower(s) and the pollinator(s). Flower provides a reward in the form of pollen and/or nectar whereas the pollinator accomplishes the process of pollination. Both these components are expected to be benefitted from each other; however, it does not always happen. The latter contention becomes evident in many situations where the visitor successfully harvests the reward by adopting an illegitimate foraging route [52, 53, $55,56]$. Here, the flower is at a disadvantage as the visitor steals/ robs its rewards without extending it the benefit of 
pollination. On the other hand, foraging through legitimate route means both the components are benefitted. Whether foraging legitimately or illegitimately, the visitor comes out with a harvest whereas the flower may or may not be benefitted from the visitor's effort. Depriving the plant of the potential benefit from the pollinator's visit would mean affecting its reproductive success [15]. There are differences in the pollen removing and deposition efficiency of the flower visitors which adversely affects their usefulness to the plant in terms of its impaired reproductive success. The capability of the visitor to contribute towards the reproductive success of the plant is its pollination efficiency (PE). The experimental perusal revealed that all the three prevailing methods of measuring the PE of the flower visitors have some good features and lack some other; the method of PTE has an edge as it has certainly a broader scope and application as is evident from Tables 5-8.

Different PTE equations are essentially based on foraging modes, foraging rates and abundances of the pollinators, and structural variations of the flowers/inflorescences. For example, in case of alfalfa (Medicago sativa) and toria (Brassica campestris), one forager at a time could work on a flower (pollination of bisexual and single flowers, the first situation, Figures 1-4), and a visitor, such as a honey bee, visiting these flowers, travelled from one flower to the other. When one kind of foraging mode was shown, as for example nectar and pollen collection in every foraging attempt, (2a) was used for deriving the PTE. Here, every foraging attempt led to successful pollination. Thus foraging rate of a species reflected its pollen transfer efficiency (see foraging rates and PTE of megachilid species in Table 5). However, when more than one foraging mode were shown by the visitors of a species simultaneously or at different hours of the day, $(2 \mathrm{~b})$ was used (see foraging modes, foraging rates, and PTE of Apis dorsata in Table 5 and Apis florea and Apis mellifera in Table 6). On the other hand, on carrot (Daucus carota) (the case of pollination of bisexual flowers which are aggregated, with exposed reproductive organs and of the sizes smaller than the pollinator, second situation), two behavior patterns were shown by the visitors: (i) nectar as well as pollen collection: they moved from one flower/floret to the other and (ii) only pollen collection: they ran/splashed over the floral disc/platform/ball and scattered pollen over several stigmas in each foraging effort (Figure 5). Under these conditions, (3) was used for the derivation of PTE of the visitors (Table 7). In bath sponge (Luffa cylindrica), the flowers were unisexual (Figure 6) (pollination of unisexual and single flowers, third situation). Here, a female flower was pollinated if a forager visited a male flower immediately before this (conditional probability: $\mathrm{P}_{\mathrm{c}}$ ), and PTE was derived by using (4a) and (4b) very much on the pattern of (2a) and (2b). The pattern of different foraging modes of pollinators visiting the flowers of bath sponge (Luffa cylindrica) and their PTE is shown in Table 8.

In this study, Medicago-Megachile and Brassica-Andrena provided suitable examples for applying (2a) whereas Medicago-Apis dorsata and Brassica-Apis were appropriate to (2b). Similarly, D. carota and its visitors represented (3) and Luffa-Xylocopa and Luffa-Melissodes represented (4a), whereas Luffa-Apis and Luffa-Halictus represented (4b). No representatives, however, were available for (5).

With the modeled PTE equations, pollination efficiency of different floral visitors of four angiosperm species under different floral situations has been calculated (Tables 5-8). The derived values using these model equations have dispelled many earlier claims. For example, the most abundant species is not necessarily the most efficient pollinator. This is true in case of Apis florea, a most abundant species, having the lowest PTE in this study. This is because a larger number of its visitors are either nectar thieves or this species has a lower foraging rate. Therefore, its contribution towards the reproductive success of these plants is relatively less than the other pollinators.

To examine the scope of modeled PTE equations in these studies (see (2a), (2b), (3), (4a), (4b), and (5), Tables 5-8), data on seed set experiments in Tables 3-5 are perused. The following points were of interest.

(i) Nectar thieves do not play any role in the pollination as these visitors do not help set seeds in the visited flowers (Tables 3-5). Therefore, PE of these visitors had zero value (Table 6). The PTE modeled in this study incorporates this point. However, the same has been overlooked in many of the earlier studies as this component of forager's behavior has not been included in other methods.

(ii) Functional roles of P- and NP-foragers were alike as both categories of visitors help set seed. However, PTE of the two kinds of visitors was different. This is because their foraging rates and the numbers differed significantly ( $\mathrm{P}>$ 0.05 , Tables $4-8$ ). The modeled PTE equations of this study have incorporated this component whereas this is missing in other studies and methods.

(iii) Single pollen transferring visit (of P-or NP-foragers) was enough for seed set in M. sativa, B. campestris, and D. carota (Tables 4 and 5). This may be due to the transfer of a fairly large number of pollen grains by the visitors (Table 2) as compared to the small number of ovules present in the ovaries of their flowers (12,24, and 2 ovules per ovary, respectively). Here, the method proposed by Spears [34] and other similar methods would fail to differentiate between the visitors of above three plants. However, the modeled PTE equations of this study effectively do this job. Likewise, in such cases, multiple visits were of little use to the flowers of these plants ( $\mathrm{P}>0.05$, Table 5). This is because the effects of pollen transferring visits of different visitors to plant species were the same and the difference was only in their foraging rates (Tables 5-8); the latter aspect has been incorporated in the present PTE modeled equations but has been ignored in the other methods.

(iv) In bath sponge (L.cylindrica), due to the presence of a large number of ovules in the ovary $(>1000)$, transfer of $>100$ pollen (grains) was essential for fruit formation in 100 percent flowers (Table 3). Here, there is a distinct role of multiple visits and the large pollen loads of pollinators of this plant (Tables $1,2$, and 4$)$. It is interesting to note that the patterns of seed set and PTE of different pollinators were similar (Tables 4 and 8). The pollinator with a greater PTE should be more useful to this plant and vice versa. 


\section{Conclusion}

From the foregoing account, it is evident that each method of measuring the pollination efficiency of flower visitors has some limitations. The 'number of pollen grains removed and deposited' and the 'seed set resulting from a single and the multiple visits' lacked a universal application. These methods were certainly appropriate in finding differences between the efficiency ranks of the pollinators of those flowers where number of deposited pollen grains was less than the number of ovules in the ovary. However, these two methods completely failed where exactly reverse situation of pollen grains and ovules existed. Thus, these two methods of measuring the PE of visitors had limited approach and lacked a universal application in the entire angiosperm taxa. On the other hand, use of 'pollen transfer efficiency' derived from the foraging behavior and abundance of the visitors seemed to have an edge over the other two methods as this was helpful in finding differences between the efficiency ranks of the pollinators of plants in all the three situations tested in this study. However, validation of all the three methods through the plant reproductive potential seemed to be an essential confirmatory step for drawing inferences about the efficiency of pollinators.

\section{Data Availability}

The data used to support the findings of this study are available from the corresponding author upon request.

\section{Conflicts of Interest}

There has not been any kind of conflicts of interest in the publication of this article.

\section{Acknowledgments}

I thank Heads, Department of Vegetable Crops, Plant Breeding, and Zoology, CCS Haryana Agricultural University, for the general and crop facilities. Special appreciations go to Professor (Dr.) N. P. Singh, Statistician, for helping in the derivation of PE model equations. Suman, Sunita, Priti, Neelam (my students), J.P.N. Chaturvedi, Jagmal Singh, Jokhu Lal, Dalbir Singh, and Sarwan Kumar (my field staff) assisted me in the field experiments. Funds for this research were utilized from 'C (a)-Zoo-2-NP (Agri)' and B (IV) NP (Agri) sponsored by the State Government of Haryana.

\section{References}

[1] K. Faegri and L. van der Pijl, The Principles of Pollination Ecology, Pergamon Press, London, UK, 1993.

[2] R. C. Sihag, "Determining the efficiency of pollinators," in Pollination Biology: Basic and Applied Principles, pp. 171-186, Rajendra Scientific Publishers, Hisar, India, 1997.

[3] S. D. Johnson and K. E. Steiner, "Generalization versus specialization in plant pollination systems," Trends in Ecology \& Evolution, vol. 15, no. 4, pp. 140-143, 2000.

[4] G. Ne'eman, A. Jürgens, L. Newstrom-Lloyd, S. G. Potts, and A. Dafni, "A framework for comparing pollinator performance: effectiveness and efficiency," Biological Reviews, vol. 85, no. 3, pp. 435-451, 2010.

[5] D. W. Schemske and C. C. Horvitz, "Variation among floral visitors in pollination ability: A precondition for mutualism specialization," Science, vol. 225, no. 4661, pp. 519-521, 1984.

[6] R. C. Sihag, "Determining the required number of pollinators for crop pollination," in Pollination Biology: Basic and Applied Principles, pp. 187-187, Rajendra Scientific Publishers, Hisar, India, 1997.

[7] R. B. Primack and J. A. Silander, "Measuring the relative importance of different pollinators to plants," Nature, vol. 255, no. 5504, pp. 143-144, 1975.

[8] A. F. Motten, "Reproduction of Erythronium umbilicatum (Liliaceae): pollination success and pollinator effectiveness," Oecologia, vol. 59, no. 2-3, pp. 351-359, 1983.

[9] A. F. Motten, D. R. Campbell, D. E. Alexander, and H. L. Miller, "Pollination effectiveness of specialist and generalist visitors to a north carolina population of Claytonia virginica," Ecology, vol. 62 , no. 5, pp. 1278-1287, 1981.

[10] R. I. Bertin, "Floral biology, hummingbird pollination and fruit production of trumpet creeper (Campsis radicans, bignoniaceae)," American Journal of Botany, vol. 69, no. 1, pp. 122-134, 1982.

[11] C. Galen and M. E. A. Newport, "Bumble bee behavior and selection on flower size in the sky pilot, Polemonium viscosum," Oecologia, vol. 74, no. 1, pp. 20-23, 1987.

[12] C. M. Herrera, "Pollinator abundance, morphology, and flower visitation rate: analysis of the 'quantity' component in a plantpollinator system,” Oecologia, vol. 80, no. 2, pp. 241-248, 1989.

[13] M. J. Couvillon, C. M. Walter, E. M. Blows, T. J. Czaczkes, K. L. Alton, and F. L. Ratnieks, "Busy bees: variation in insect flowervisiting rates across multiple plant species," Psyche: A Journal of Entomology, vol. 2015, pp. 1-7, 2015.

[14] L. W. Macior, "Pollen-foraging behavior of Bombus in relation to pollination of nototribic flowers," American Journal of Botany, vol. 54, no. 3, pp. 359-364, 1967.

[15] M. M. Mayfield, N. M. Waser, and M. V. Price, "Exploring the 'most effective pollinator principle' with complex flowers: Bumblebees and Ipomopsis aggregata," Annals of Botany, vol. 88, no. 4, pp. 591-596, 2001.

[16] C. T. Ivey, P. Martinez, and R. Wyatt, "Variation in pollinator effectiveness in swamp milkweed, Asclepias incarnata (Apocynaceae)," American Journal of Botany, vol. 90, no. 2, pp. 214-225, 2003.

[17] J. K. Conner, R. Davis, and S. Rush, "The effect of wild radish floral morphology on pollination efficiency by four taxa of pollinators," Oecologia, vol. 104, no. 2, pp. 234-245, 1995.

[18] N. Muchhala and M. D. Potts, "Character displacement among bat-pollinated flowers of the genus Burmeistera: Analysis of mechanism, process and pattern," Proceedings of the Royal Society B Biological Science, vol. 274, no. 1626, pp. 2731-2737, 2007.

[19] J. G. Ehrenfeld, "Pollination of three species of Euphorbia subgenus chamaesyce, with special reference to bees," The American Midland Naturalist, vol. 101, no. 1, p. 87, 1979.

[20] R. C. Sihag and A. Rathi, "Diversity, abundance, foraging behaviour and pollinating efficiency of different bees visiting pigeon pea (Cajanus cajan (L) Millsp.) blossoms," Indian Bee Journal, vol. 56, pp. 187-201, 1994.

[21] N. Chaudhary, R. C. Sihag, and M. C. Pandey, "Relative abundance, diversity and dominance concentration of two honeybee 
species on three concurrently flowering crops onion (Allium cepa L.), carrot (Daucus carota L.) and fennel (Foeniculum vulgare L.)," Pestology, vol. 33, no. 7, pp. 9-13, 2009.

[22] N. Wadhwa and R. C. Sihag, "Psychophilous mode of pollination predominates in sarpagandha (Rouvolfia serpentina)," Journal of Entomology, vol. 9, no. 4, pp. 187-207, 2012.

[23] N. Wadhwa and R. C. Sihag, "Melittophilous mode of pollination predominates in European plum (Prunus domestica L.) in the semi-arid environment of Northwest India," Asian Journal of Agricultural Research, vol. 9, no. 5, pp. 189-207, 2015.

[24] W. C. Adlerz, "Honey bee visit numbers and watermelon pollination1," Journal of Economic Entomology, vol. 59, no. 1, pp. 28-30, 1966.

[25] D. W. Schemske, "Flowering Phenology and Seed Set in Claytonia virginica (Portulacaceae)," Bulletin of the Torrey Botanical Club, vol. 104, no. 3, p. 254, 1977.

[26] N. M. Waser and L. A. Real, "Effective mutualism between sequentially flowering plant species," Nature, vol. 281, no. 5733, pp. 670-672, 1979.

[27] H. F. Sahli and J. K. Conner, "Visitation, effectiveness, and efficiency of 15 genera of visitors to wild radish, Raphanuss raphanistrum (Brassicaceae)," American Journal of Botany, vol. 94, no. 2, pp. 203-209, 2007.

[28] K. Daly, M. Pacheco, A. Poplack et al., "Comparing Apis mellifera and Bombus spp. pollination efficiencies on willamette valley blueberry farms," Oregon Undergraduate Research Journal, vol. 4, no. 1, 2013.

[29] R. Radera, I. Bartomeus, L. A. Garibaldi, M. P. D. Garratt, B. G. Howlett, R. l. Winfree et al., "Non-bee insects are important contributors to global crop pollination," http://www.pnas.org/ content/113/1/146, 2015.

[30] S. K. Santos and M. Gimenes, "The efficiency of bees in pollinating ephemeral flowers of Jacquemontia bracteosa (Convolvulaceae)," Iheringia. Série Zoologia, vol. 106, no. 0, 2016.

[31] H. Wang, G.-X. Cao, L.-L. Wang, Y.-P. Yang, Z.-Q. Zhang, and Y.-W. Duan, "Evaluation of pollinator effectiveness based on pollen deposition and seed production in a gynodieocious alpine plant, Cyananthus delavayi," Ecology and Evolution, vol. 7, no. 20, pp. 8156-8160, 2017.

[32] R. Ornduff, "Complementary roles of halictids and syrphids in the pollination of Jepsonia heterandra(Saxifragaceae)," Evolution, vol. 29, no. 2, pp. 371-373, 1975.

[33] G. Meerabai, "Visitation rate, effectiveness and efficiency of pollinators to Cadaba fruiticosa (Linn) Druce," The Bioscan, vol. 7, no. 3, pp. 483-485, 2012.

[34] E. E. Spears Jr., "A direct measure of pollinator effectiveness," Oecologia, vol. 57, no. 1-2, pp. 196-199, 1983.

[35] D. H. Morse and R. S. Fritz, "Contributions of diurnal and nocturnal insects to the pollination of common milkweed (Asclepias syriaca L.) in a pollen-limited system," Oecologia, vol. 60, no. 2, pp. 190-197, 1983.

[36] B. J. Sampson and J. H. Cane, "Pollination efficiencies of three bee (Hymenoptera: Apoidea) species visiting rabbiteye blueberry," Journal of Economic Entomology, vol. 93, no. 6, pp. 1726-1731, 2000.

[37] S. Krishnan, C. G. Kushalappa, R. U. Shaanker, and J. Ghazoul, "Status of pollinators and their efficiency in coffee fruit set in a fragmented landscape mosaic in South India," Basic and Applied Ecology, vol. 13, no. 3, pp. 277-285, 2012.

[38] J. A. Silander and R. B. Primack, "Pollination Intensity and Seed Set in the Evening Primrose (Oenothera fruticosa)," The American Midland Naturalist, vol. 100, no. 1, p. 213, 1978.
[39] G. Kudo, A. S. Hirao, and Y. Kawai, "Pollination efficiency of bumblebee Queens and workers in the alpine shrub Rhododendron aureum," International Journal of Plant Sciences, vol. 172, no. 1, pp. 70-77, 2011.

[40] B. Donovan and P. Read, "Efficacy of honey bees as pollinators of kiwifruit," Acta Horticulturae, no. 288, pp. 220-224, 1991.

[41] R. C. Sihag, "Why should beekeeping be utilized as an input in agriculture?" Current Science, vol. 81, no. 12, pp. 1514-1516, 2001.

[42] R. C. Sihag, "Problem of wax moth (Galleria mellonella L.) in the colonies of giant honeybee, Apis dorsata in Haryana," Indian Bee Journal, vol. 44, pp. 107-109, 1982.

[43] R. C. Sihag, "Floral biology, melittophily and pollination ecology of cultivated cruciferous crops," in Recent Advances in Pollen Research, T. M. Varghese, Ed., pp. 241-268, Allied Publishers, New Delhi, India, 1985.

[44] R. C. Sihag, "Floral biology, melittophily and pollination ecology of cultivated umbelliferous crops," in Recent Advances in Pollen Research, T. M. Varghese, Ed., pp. 269-277, Allied Publishers, New Delhi, India, 1985.

[45] R. C. Sihag, "Behaviour and ecology of the subtropical carpenter bee, Xylocopa fenestrata F. 6. Foraging dynamics, crop hosts and pollination potential," Journal of Apicultural Research, vol. 32, no. 2, pp. 94-101, 1993.

[46] F. D. Parker, "How efficient are bees in pollinating sunflowers?" Journal of the Kansas Entomological Society, vol. 54, no. 1, pp. 61-67, 1981.

[47] F. D. Parker, "Efficiency of bees in pollinating onion flowers," Journal of Kansas Entomological Society, vol. 55, no. 1, pp. 171$176,1982$.

[48] M. Fuentes, "Cell counting with a hemocytometer; Hemocytometer calculation tutorial," Hemocytometer, 2018, https:// www.hemocytometer.org/hemocytometer-calculation-tutorial/.

[49] R. C. Sihag, "Insect pollination increases seed production in cruciferous and umbelliferous crops," Journal of Apicultural Research, vol. 25, no. 2, pp. 121-126, 1986.

[50] D. W. Inouye, “The terminology of floral larceny," Ecology, vol. 61, no. 5, pp. 1251-1253, 1980.

[51] W. S. Robinson, "Effects of apple cultivar on foraging behavior and pollen transfer by honey bees," Journal of American Society of Horticulture Science, vol. 104, pp. 596-598, 1979.

[52] R. C. Sihag, "Characterization of the pollinators of cultivated cruciferous and leguminous crops of sub-tropical Hisar (India)," Bee World, vol. 69, no. 4, pp. 153-158, 1988.

[53] R. C. Sihag and S. Shivrana, "Foraging behaviour and strategies of the flower visitors," in Pollination Biology: Basic and Applied Principles, R. C. Sihag, Ed., pp. 53-73, Rajendra Scientific Publishers, Hisar, India, 1997.

[54] G. W. Snedecor and W. G. Cochran, Statistical Methods, IBH Publishing Company, New Delhi: Oxford, 6th edition, 1967.

[55] R. E. Irwin, J. L. Bronstein, J. S. Manson, and L. Richardson, "Nectar robbing: Ecological and evolutionary perspectives," Annual Review of Ecology, Evolution and Systematics, vol. 41, pp. 271-292, 2010.

[56] B. Moisset, "Pollinators and nectar robbers," http://nativeplantwildlifegarden.com/pollinators-and-nectar-robbers/, 2012. 

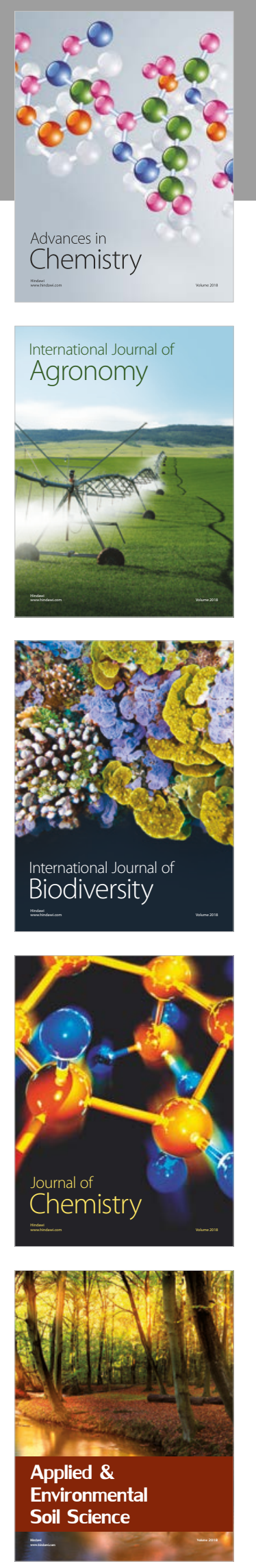

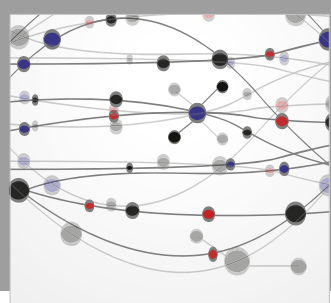

The Scientific World Journal

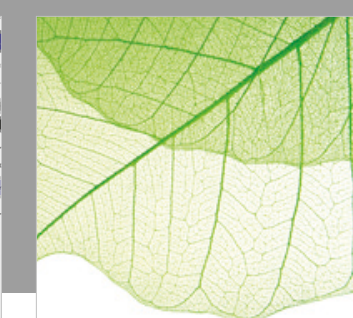

Journal of Botany

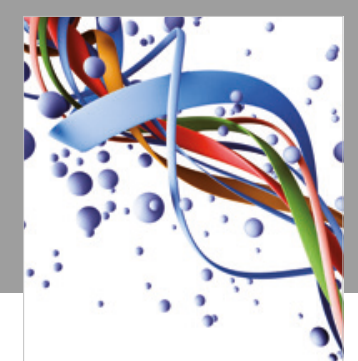

Scientifica

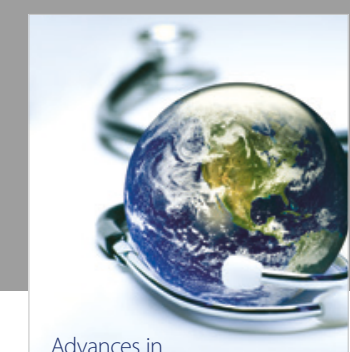

Public Health

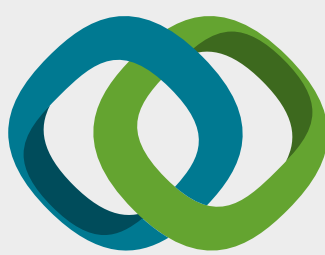

Hindawi

Submit your manuscripts at

www.hindawi.com
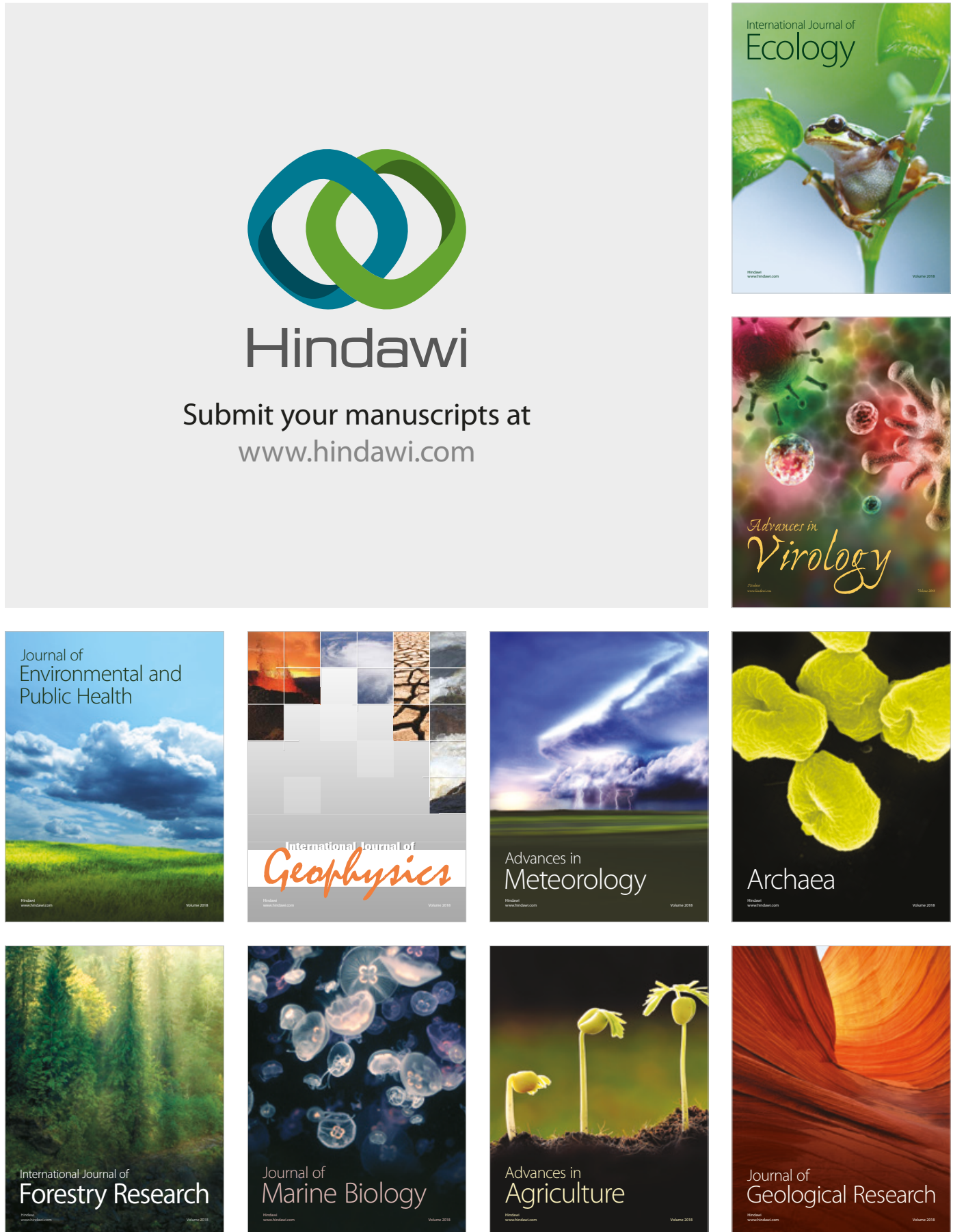

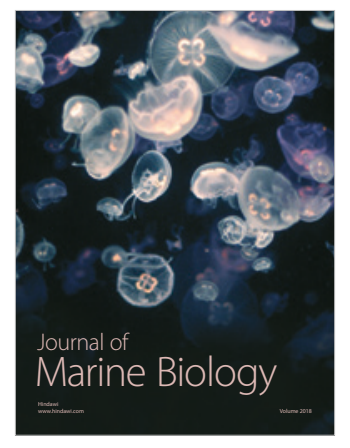

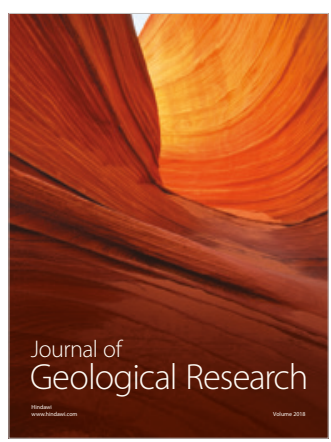

